\title{
Biomarkers Changes after Neoadjuvant Chemotherapy in Breast Cancer: A Seven-Year Single Institution Experience
}

\author{
Saverio Coiro ${ }^{1,2, \dagger}$, Elisa Gasparini ${ }^{2,3, \dagger}$, Giuseppe Falco ${ }^{1,2}$, Giacomo Santandrea $4,5, * \mathbb{C}$, Moira Foroni ${ }^{2,4}$, \\ Giulia Besutti $^{6}$, Valentina Iotti ${ }^{2,6}$, Roberto Di Cicilia ${ }^{2,3}$, Monica Foroni ${ }^{1,2}$, Simone Mele ${ }^{1,2}$, Guglielmo Ferrari ${ }^{1,2}$, \\ Giancarlo Bisagni ${ }^{2,3}$ and Moira Ragazzi ${ }^{2,4}$ (D)
}

1 Breast Surgery Unit, Azienda Unità Sanitaria Locale-IRCCS di Reggio Emilia, 42123 Reggio Emilia, Italy; saverio.coiro@ausl.re.it (S.C.); giuseppe.falco@ausl.re.it (G.F.); monica.foroni@ausl.re.it (M.F.); simone.mele@ausl.re.it (S.M.); guglielmo.ferrari@ausl.re.it (G.F.)

2 Breast Cancer Unit, Azienda Unità Sanitaria Locale-IRCCS di Reggio Emilia, 42123 Reggio Emilia, Italy; elisa.gasparini@ausl.re.it (E.G.); moira.foroni@ausl.re.it (M.F.); valentina.iotti@ausl.re.it (V.I.); roberto.dicicilia@ausl.re.it (R.D.C.); giancarlo.bisagni@ausl.re.it (G.B.); moira.ragazzi@ausl.re.it (M.R.)

3 Oncology Unit, Azienda Unità Sanitaria Locale-IRCCS di Reggio Emilia, 42123 Reggio Emilia, Italy

4 Pathology Unit, Azienda Unità Sanitaria Locale-IRCCS di Reggio Emilia, 42123 Reggio Emilia, Italy

5 Clinical and Experimental Medicine Ph.D. Program, University of Modena and Reggio Emilia, 41100 Modena, Italy

6 Radiology Unit, Azienda Unità Sanitaria Locale-IRCCS di Reggio Emilia, 42123 Reggio Emilia, Italy; giulia.besutti@ausl.re.it

check for updates

Citation: Coiro, S.; Gasparini, E.; Falco, G.; Santandrea, G.; Foroni, M.; Besutti, G.; Iotti, V.; Di Cicilia, R.; Foroni, M.; Mele, S.; et al. Biomarkers Changes after Neoadjuvant Chemotherapy in Breast Cancer: A Seven-Year Single Institution Experience. Diagnostics 2021, 11, 2249. https://doi.org/10.3390/

diagnostics11122249

Academic Editor: Gary J. Whitman

Received: 16 October 2021

Accepted: 26 November 2021

Published: 30 November 2021

Publisher's Note: MDPI stays neutral with regard to jurisdictional claims in published maps and institutional affiliations.

Copyright: (C) 2021 by the authors. Licensee MDPI, Basel, Switzerland. This article is an open access article distributed under the terms and conditions of the Creative Commons Attribution (CC BY) license (https:// creativecommons.org/licenses/by/ $4.0 /)$.
* Correspondence: giacomo.santandrea@ausl.re.it; Tel.: +39-05-2229-6364

+ These authors equally contributed to this work.

\begin{abstract}
The adoption of neoadjuvant chemotherapy (NACT) for breast cancer (BC) is increasing. The need to repeat the biomarkers on a residual tumor after NACT is still a matter of debate. We verified estrogen receptors (ER), progesterone receptors (PR), Ki67 and human epidermal growth factor receptor 2 (HER2) status changes impact in a retrospective monocentric series of $265 \mathrm{BCs}$ undergoing NACT. All biomarkers changed with an overall tendency toward a reduced expression. Changes in PR and Ki67 were statistically significant $(p=0.001)$. Ki67 changed in 114/265 (43.0\%) cases, PR in 44/265 (16.6\%), ER in 31/265 (11.7\%) and HER2 in 26/265 (9.8\%). Overall, intrinsic subtype changed in 72/265 (27.2\%) cases after NACT, and 10/265 (3.8\%) cases switched to a different adjuvant therapy accordingly. Luminal subtypes changed most frequently $(66 / 175 ; 31.7 \%)$ but with less impact on therapy (5/175; $2.8 \%)$. Only 3 of 58 triple-negative BCs $(5.2 \%)$ changed their intrinsic subtype, but all of them switched treatment. No correlation was found between intrinsic subtype changes and clinicopathological features. To conclude, biomarkers changes with prognostic implications occurred in all BC intrinsic subtypes, albeit they impacted therapy mostly in HER2 negative and/or hormone receptors negative BCs. Biomarkers retesting after NACT is important to improve both tailored adjuvant therapies and prognostication of patients.
\end{abstract}

Keywords: ER; HER2; PR; ki67; breast cancer; immunohistochemistry; neoadjuvant therapy

\section{Introduction}

The indications for neoadjuvant chemotherapy (NACT) in breast cancer have been implemented since 2006 [1]. Besides the traditional aims of tumor downsizing, downstaging and conservative surgery, the NACT setting has become an opportunity for in vivo assessment of a tumor's response to standard treatment and newly developed therapy.

Thought to have equal survival rates as adjuvant cytotoxic chemotherapy, NACT could provide an important indicator of patient's outcome since the pathological complete response (pCR) is a powerful prognostic predictor of better disease-free and overall survival, compared with the evidence of residual tumor after NACT [2-5]. Finally yet importantly, the adjuvant therapy regimen could be modulated based on response to NACT. 
For these reasons, the adoption of NACT for breast cancer patients has substantially increased in our institution in the last few years. Both NACT and adjuvant therapies are mainly based on the assessment of three biomarkers on tumor tissue from preoperative biopsies worldwide: estrogen receptors (ER), progesterone receptors (PR) and HER2 status [6,7]. Ki67 is implemented as a fourth biomarker by the majority of European countries in this setting to subdivide tumors into five surrogated intrinsic subtypes with different prognosis and treatment implications: Luminal A-like, Luminal B-like HER2 negative, Luminal B-like HER2 positive, HER2-positive non-luminal and triple-negative [8]. The need to repeat these biomarkers after NACT is still a matter of debate, and currently, no univocal international guidelines regarding this topic have been introduced.

To date, in our institution, all four biomarkers have been systematically repeated in all cases of residual tumor after NACT.

Thus, the aims of this study were to verify in a large retrospective monocentric series of breast carcinoma undergoing NACT:

- the concordance/discordance rate of each tumor biomarker between pre-NACT biopsy and post-NACT surgical specimen;

- the effect of biomarker changes on intrinsic subtype;

- the impact of these changes in the "real-world" of adjuvant treatment, also in view of new literature evidence.

\section{Materials and Methods}

This retrospective study was performed in accordance with the Declaration of Helsinki and approved by the Institutional Board Review (Ethical Committee Number 305/2019/ OSS/IRCCSRE).

\subsection{Case Selection}

The pathology and oncology databases were searched in our Institution (AUSL-IRCCS, Reggio Emilia, Italy) for patients with breast carcinoma who underwent NACT followed by breast surgery between 2011 and 2018. Patients with a pCR were excluded from the present study: pCR was determined according to the most widely accepted definition that considers the absence of residual invasive disease in the breast plus the absence of measurable disease in any axillary lymph node (ypT0N0); the possible presence of carcinoma in situ (ypTisN0) was also included in the definition since it has no impact in patient prognosis [9]. Tumor biomarkers were performed on both pre-NACT biopsy and post-NACT surgical specimens. Clinicopathological data were collected from electronic archives and included: patient sex and age, cancer stage, treatment type, tumor size, histologic subtype (NST, lobular, other), ER, PR, KI67 and HER2 status. Patients received NACT according to standard protocol of our Institution based on the current guidelines or within clinical trials as follows: 4-6 months of pre-operative treatment, based on anthracyclines and taxanes, with the addition of anti-HER2 targeted therapy if indicated.

\subsection{Pathological Analysis}

Tumor grade was assessed according to the Nottingham modification of the BloomRichardson (Elston and Ellis) system. Immunohistochemistry for ER (SP1, Ventana prediluted), PR (1E2, Ventana prediluted) and Ki67 (MIB-1, 1:100, Dako) was performed using standard protocols in an automated immunostainer (Ventana BenchMark, Tucson, AZ, USA); 3, 3' - diaminobenzidine was used as the chromogen and Harris's hematoxylin as the counterstain. Testing of hormones receptors was performed following ASCO-CAP recommendations [10]. HER2 status was evaluated using frontline dual-color FISH (FDA-approved Vysis PathVysion Her-2 DNA probe kit, Abbott Laboratories, Abbott Park, IL, USA) as previously described [11] and reported in accordance with ASCO-CAP guidelines [12].

Tumors were classified according to the St. Gallen surrogate definition of intrinsic subtypes of breast cancer in [8]: luminal A-like (ER and PR positive/HER2 negative/Ki-67 < 20\%), luminal B-like/HER2-negative (ER positive/HER2-negative/Ki-67 $\geq 20 \%$ or PR $\leq 20 \%$ ), 
luminal B-like/HER2-positive (ER positive/HER2 positive), HER2-positive/non-luminal (ER and PR negative/HER2 positive) and triple-negative (TN) (ER, PR and HER2 negative).

Clinical and pathological stages were assessed according to the American Joint Committee on Cancer Staging (8th edition) [13].

\subsection{Statistical Analysis}

The results were analyzed in GraphPad Prism (v5.0, GraphPad Software Inc., San Diego, CA, USA) and SPSS Statics v22.0.

Statistically significant differences in tumor histotypes and grading pre- and postNACT were assessed using the Pearson's Chi-Squared test. A comparison of the biomarkers' statuses between pre-NACT and post-NACT was performed using Fisher's exact test and the Wilcoxon's $t$-test. The correlation between intrinsic subtype change after NACT and clinicopathological features was evaluated using a $t$-test. Data were considered statistically significant with a $p$-value $<0.05$. Regression analysis was also performed to further investigate a potential correlation between intrinsic subtype changes and age.

Concordance analysis of biomarkers status and intrinsic subtypes between pre- and post-NACT were assessed by Cohen's Unweighted Kappa.

\section{Results}

\subsection{Study Cohort}

A total of 405 consecutive patients underwent NACT for breast cancer between January 2011 and December 2018 in our Institution. Patients whose surgical specimen was missing (metastatic progression, patient refusing surgery, migration to another hospital) $(n=12)$ and patients who had a pCR $(n=129)$ were excluded (Figure 1$)$. Thus, we included in our study 264 patients with 265 carcinomas (one patient had bilateral synchronous tumors at presentation, both luminal B-HER2 positive). The patients were 263 females and 1 male, aged 25 to 86 years old (mean $53.88 \pm 13.20$ ). The clinical, histological and biological characteristics pre- and post-NACT are reported in Table 1.

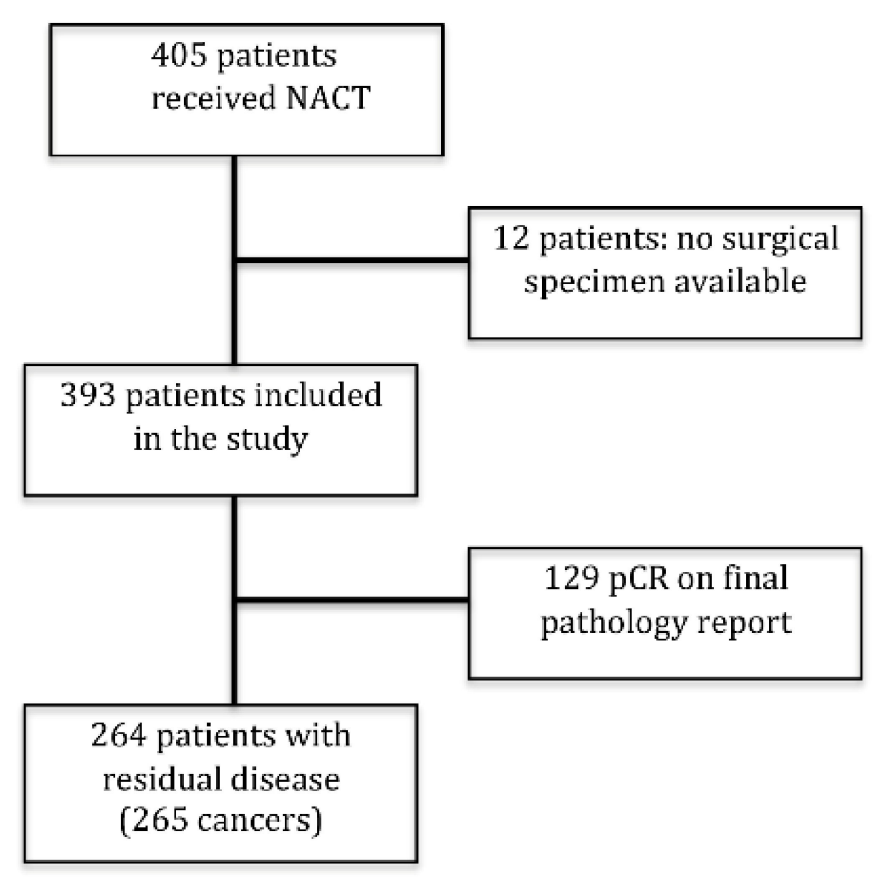

Figure 1. Case selection: among 405 consecutive patients undergoing NACT for breast cancer (January 2011-December 2018), 141 patients were excluded: 12 patients without surgical specimen (metastatic progression, surgery refusal, migration to another hospital), and 129 patients who had a pathological complete response (pCR). Therefore, 265 breast cancers from 264 patients (one patient had a bilateral tumor at presentation) were examined in the present study. 
Table 1. Clinicopathological features of the cohort (265 tumors from 264 patients) pre- and post-neoadjuvant chemotherapy.

\begin{tabular}{|c|c|c|c|c|}
\hline \multicolumn{2}{|c|}{ PRE-NACT } & \multicolumn{2}{|c|}{ POST-NACT } & \multirow{2}{*}{$p$-Value } \\
\hline FEATURES & RESULTS & FEATURES & RESULTS & \\
\hline \multicolumn{5}{|l|}{ Stage } \\
\hline IA & 4 & IA & 103 & \multirow{7}{*}{ NA } \\
\hline IIA & 93 & IB & 2 & \\
\hline IIB & 93 & IIA & 76 & \\
\hline IIIA & 59 & IIB & 24 & \\
\hline \multirow[t]{3}{*}{ IIIB } & 16 & IIIA & 41 & \\
\hline & & IIIB & 4 & \\
\hline & & IIIC & 15 & \\
\hline \multicolumn{5}{|l|}{ TNM } \\
\hline cT1c & 5 & урT0 & $4^{*}$ & \multirow{10}{*}{ NA } \\
\hline cT2 & 183 & ypT1 & 162 & \\
\hline cT3 & 63 & урT2 & 70 & \\
\hline \multirow[t]{2}{*}{ cT4 } & 14 & урT3 & 22 & \\
\hline & & урT4 & 6 & \\
\hline cN0 & 116 & ypN0 & 141 & \\
\hline \multirow[t]{4}{*}{$\mathrm{cN}+$} & 149 & ypN1 & 71 & \\
\hline & & ypN2 & 35 & \\
\hline & & ypN3 & 15 & \\
\hline & & $\mathrm{ypNx}$ & 4 & \\
\hline \multicolumn{5}{|l|}{ Histology } \\
\hline NST & $244(92.1 \%)$ & & $244(92.1 \%)$ & \multirow{5}{*}{$0.988^{\circ}$} \\
\hline ILC & $16(6.0 \%)$ & & $17(6.4 \%)$ & \\
\hline Metaplastic & $1(0.4 \%)$ & & $1(0.4 \%)$ & \\
\hline NST + ILC & $3(1.1 \%)$ & & $2(0.8 \%)$ & \\
\hline Mucinous & $1(0.4 \%)$ & & $1(0.4 \%)$ & \\
\hline \multicolumn{5}{|l|}{ Grading } \\
\hline G1 & 0 & & 3 & \multirow{3}{*}{$0.158^{\circ}$} \\
\hline G2 & 148 & & 137 & \\
\hline G3 & 117 & & 125 & \\
\hline ER range (mean) & $\begin{array}{c}0-100 \\
(57.1 \pm 43.8)\end{array}$ & & $\begin{array}{c}0-100 \\
(56.5 \pm 44.3)\end{array}$ & $0.20^{\wedge}$ \\
\hline$<1 \%$ & 77 & & 84 & \multirow{2}{*}{$0.571 \S$} \\
\hline$\geq 1 \%$ & 188 & & 181 & \\
\hline PR range (mean) & $\begin{array}{c}0-100 \\
(31.0 \pm 37.9)\end{array}$ & & $\begin{array}{c}0-100 \\
(19.6 \pm 31.7)\end{array}$ & $<0.0001^{\wedge}$ \\
\hline$<20 \%$ & 147 & & 186 & \multirow{2}{*}{$0.0006 \S$} \\
\hline$\geq 20 \%$ & 118 & & 79 & \\
\hline Ki67 range (mean) & $\begin{array}{c}4-95 \\
(36.9 \pm 22.1)\end{array}$ & & $\begin{array}{c}0-90 \\
(27.4 \pm 27.3)\end{array}$ & $<0.0001^{\wedge}$ \\
\hline$<20 \%$ & 46 & & 144 & \multirow{2}{*}{$<0.0001 \S$} \\
\hline$\geq 20 \%$ & 219 & & 121 & \\
\hline \multicolumn{5}{|l|}{ HER2 } \\
\hline POS & 105 & & 91 & \multirow{2}{*}{$0.15 \S$} \\
\hline NEG & 160 & & 174 & \\
\hline
\end{tabular}

ER: estrogen receptor; PR: progesterone receptor; ILC: invasive lobular carcinoma; IND: indeterminate; NA: Not Assessed; NACT: neoadjuvant chemotherapy; NEG: negative; NST: carcinoma of non-special type; POS: positive. * cases with residual disease in lymph nodes. Significant $p$-values are in bold. ${ }^{\circ}$ Pearson's Chi-squared; ^ Wilcoxon signed-rank test; $§$ Fisher's Exact Test. 
The clinical stage at presentation was mainly stage II and III: 186 (70.2\%) cases were stage II A/B, and 75 (28.3\%) cases were stage III A/B. Of note, four (1.5\%) cases of carcinoma stage IA were treated with NACT because of aggressive features. After NACT, cases were mainly stage I and II: 105 (39.6\%) cases were stage I A/B, and 100 (37.7\%) were stage II A/B. Overall, tumor downstaging occurred in $166(62.6 \%)$ cases, whereas 40 (15.1\%) cases showed progression, in the remaining cases tumor stage remained unmodified (data not shown).

After NACT, the majority of tumors were ypT1 (61.1\%) and ypN0 (53.2\%). Four cases showed a pT0 on the breast but a residual disease in lymph nodes; among them, three were triple-negative, and the other one was Luminal B Her2+. In these cases, residual disease in lymph nodes was characterized.

The invasive cancer histotype was NST in $244(92.1 \%)$ cases, lobular in $16(6.0 \%)$ cases, mixed NST and lobular in $3(1.1 \%)$ cases, while the remaining $2(0.8 \%)$ cases were 1 mucinous and 1 metaplastic carcinoma. After NACT, the tumor histotype was manly confirmed, except in five cases. Namely, one case of NST and one case of ILC were diagnosed as mixed after NACT, whereas three cases of mixed NST and lobular type carcinoma on biopsy showed only NST carcinoma on surgical specimen.

Concerning the pre/post-NACT biomarkers modification, we observed a slight reduction in ER mean expression (57.1\% vs. $56.5 \%, p=0.52)$ as an overall increase in ER-negative cases (77 vs. $84, p=0.57$ ), albeit not statistically significant. Contrariwise, a significant decrease in PR (31.0\% vs. 19.6\%, $p=0.001)$ and Ki67 mean expression (36.9 vs. 27.5, $p=0.001)$ were documented. Furthermore, a statistically significant increase in cases with low PR and Ki67 expression was observed: cases with PR $<20 \%$ were 146 pre-NACT and 186 post-NACT and cases with Ki67 < 20\% were 46 pre-NACT and 144 post-NACT. Regarding HER2 status, after NACT, we observed a slight reduction in HER2 positive cases (105 vs. 91 cases, $p=0.13$ ).

\subsection{Change in Biomarkers Status}

Changes in ER, PR and HER2 status (negative to positive or positive to negative) were observed in $31(11.7 \%), 44(16.6 \%)$ and 26 (9.8\%) cases, respectively (Table 2). Among hormone receptors, progesterone receptors changed more frequently than estrogen receptors. Ki67 changed cut-off in 114 (43.0\%) cases, becoming <20\% in 106 (93.0\%) cases. Thus, overall, a trend towards a negative shift was observed in hormone receptors and HER2, as well as a shift towards Ki67-low values post-NACT. Of note, $12(4.5 \%)$ cases became ER-positive, $8(3.0 \%)$ cases PR-positive, 8 (3.0\%) cases Ki67-high and 6 (2.3\%) cases HER2 positive. Concordance analysis demonstrated that HER2 was the most stable biomarker ( $K 0.79)$, whereas $\mathrm{Ki} 67$ was the most prone to change $(\mathrm{K} 0.186)$ from pre-NACT biopsy to post-NACT surgical specimen.

Table 2. Changes in the status of biomarkers between pre-NACT biopsy and post-NACT resection.

\begin{tabular}{cccccc}
\hline $\begin{array}{c}\text { Biomarkers } \\
\text { (Cut-off) }\end{array}$ & Pre-NACT & Post-NACT & N (\%) & \% of Concordance & K [0.95 CI] \\
\hline ER & + & + & $169(63.8)$ & & \\
$(\geq 1 \%)$ & + & - & $65(24.5)$ & 88.3 & 0.723 \\
& - & - & $19(7.2)$ & & \\
\hline & + & + & $119(44.5)$ & & \\
$(\geq 1 \%)$ & - & - & $102(38.5)$ & & $0.632-0.815]$ \\
& + & - & $36(13.6)$ & & {$[0.581-0.759]$} \\
\hline
\end{tabular}


Table 2. Cont.

\begin{tabular}{cccccc}
\hline $\begin{array}{c}\text { Biomarkers } \\
\text { (Cut-off) }\end{array}$ & Pre-NACT & Post-NACT & N (\%) & \% of Concordance & K [0.95 CI] \\
\hline & + & + & $72(27.2)$ & & \\
PR & - & - & $140(52.8)$ & 80.0 & [0.481-0.682] \\
$(\geq 20 \%)$ & + & - & $46(17.4)$ & & \\
& - & + & $7(2.6)$ & & \\
\hline & + & + & $113(42.7)$ & & 0.186 \\
Ki67 & - & - & $38(14.3)$ & 57.0 & \\
$(\geq 20 \%)$ & + & - & $106(40.0)$ & & \\
& - & + & $8(3.0)$ & & \\
& + & + & $85(32.1)$ & & \\
& - & - & $154(58.1)$ & & \\
HER2 & + & - & $20(7.5)$ & & \\
& - & + & $6(2.3)$ & & \\
\hline
\end{tabular}

K of concordance: Cohen's Unweighted Kappa.

\subsection{Change in Intrinsic Subtype and Therapy}

Table 3 describes intrinsic subtype changes and their impact on adjuvant therapy.

Table 3. Intrinsic subtype changes and their impact on adjuvant therapy.

\begin{tabular}{|c|c|c|c|c|c|c|c|c|}
\hline \multirow{2}{*}{$\begin{array}{c}\text { Pre-NACT } \\
\text { Intrinsic } \\
\text { Subtype }\end{array}$} & \multirow[b]{2}{*}{$\begin{array}{c}N^{\circ} \text { Cases } \\
(\%)\end{array}$} & \multirow[b]{2}{*}{$\begin{array}{c}\text { No Change } \\
(\%)\end{array}$} & \multirow[b]{2}{*}{$\begin{array}{c}\text { Yes Change } \\
(\%)\end{array}$} & \multicolumn{2}{|c|}{ Post-NACT } & \multirow[b]{2}{*}{ Therapy Added } & \multicolumn{2}{|c|}{$\begin{array}{c}\text { Intrinsic Subtype } \\
\text { Agreement }\end{array}$} \\
\hline & & & & $\begin{array}{c}\text { Intrinsic } \\
\text { Subtype (n) }\end{array}$ & $\begin{array}{c}\text { Therapy } \\
\text { Change (n) }\end{array}$ & & $\begin{array}{l}\% \text { of Con- } \\
\text { cordance }\end{array}$ & $\mathrm{K}[0.95 \mathrm{CI}]$ \\
\hline Lum A & $20(7.5)$ & $13(65.0)$ & $7(35.0)$ & Lum B (7) & 0 & None & $84.9 \%$ & $\begin{array}{c}0.323 \\
{[0.129-0.516]}\end{array}$ \\
\hline $\begin{array}{l}\text { Lum B } \\
\text { HER2- }\end{array}$ & $82(30.9)$ & $51(62.2)$ & $31(37.8)$ & $\begin{array}{c}\text { Lum A (22) } \\
\text { Lum A } \\
\text { HER2+ (2) } \\
\text { Lum B } \\
\text { HER2+ (3) } \\
\text { TN (4) }\end{array}$ & $\begin{array}{l}0 \\
2 \\
3 \\
0\end{array}$ & $\begin{array}{c}\text { None } \\
\text { Trastuzumab } \\
\text { Trastuzumab } \\
\text { None }\end{array}$ & $81.1 \%$ & $\begin{array}{c}0.54 \\
{[0.425-0.655]}\end{array}$ \\
\hline $\begin{array}{l}\text { Lum B } \\
\text { HER2+ }\end{array}$ & $73(27.6)$ & $45(61.6)$ & $28(38.4)$ & $\begin{array}{c}\text { Lum A (11) } \\
\text { Lum A } \\
\text { HER2+ (5) } \\
\text { Lum B } \\
\text { HER2- (8) } \\
\text { HER2+ (4) }\end{array}$ & $\begin{array}{l}0 \\
0 \\
0 \\
0\end{array}$ & $\begin{array}{l}\text { None } \\
\text { None } \\
\text { None } \\
\text { None }\end{array}$ & $86.0 \%$ & $\begin{array}{c}0.62 \\
{[0.506-0.733]}\end{array}$ \\
\hline HER2+ & $32(12.1)$ & $29(90.6)$ & $3(9.4)$ & $\begin{array}{l}\text { Lum B } \\
\text { HER2- (2) } \\
\text { TN (1) }\end{array}$ & $\begin{array}{l}2 \\
0\end{array}$ & $\begin{array}{l}\text { Hormonal therapy } \\
\text { None }\end{array}$ & $97.4 \%$ & $\begin{array}{c}0.877 \\
{[0.788-0.967]}\end{array}$ \\
\hline $\mathrm{TN}$ & $58(21.9)$ & $55(94.8)$ & $3(5.2)$ & $\begin{array}{c}\text { Lum B } \\
\text { HER2- (2) } \\
\text { Lum B } \\
\text { HER2+ (1) }\end{array}$ & $\begin{array}{l}2 \\
1\end{array}$ & $\begin{array}{l}\text { Hormonal therapy } \\
\text { Trastuzumab and } \\
\text { Hormonal therapy }\end{array}$ & $97.0 \%$ & $\begin{array}{c}0.913 \\
{[0.853-0.972]}\end{array}$ \\
\hline $\begin{array}{c}\text { Total } \\
(\%)\end{array}$ & $265(100)$ & $193(72.8)$ & $72(27.2)$ & & $\begin{array}{c}10 \\
(3.8)\end{array}$ & & $72.8 \%$ & $\begin{array}{c}0.656 \\
{[0.588-0.724]}\end{array}$ \\
\hline
\end{tabular}

Lum A, Luminal A-like; Lum B HER2 -, Luminal B-like HER2-negative; Lum B HER2 +, Luminal B-like HER2-positive; HER2+, HER2positive non-luminal; TN, Triple-negative. K of concordance: Cohen's Unweighted Kappa.

At diagnosis, the majority of tumors were Luminal B-like Her2-negative (30.9\%) and Luminal B-like Her2-positive (27.6\%). Fifty-eight (21.9\%) cases were triple-negative and $32(12.1 \%)$ were HER2-positive/non-luminal. Twenty $(7.5 \%)$ cases of luminal A-like carcinomas were treated with NACT because of advanced stage. 
Overall, among all 265 carcinomas, the intrinsic subtype changed in $72(27.2 \%)$ cases after NACT. Among these, $10(3.8 \%)$ cases switched to a different adjuvant therapy, accordingly. Namely, in six cases, HER2-positivity was documented after NACT; thus, trastuzumab was added to the adjuvant chemotherapy protocol; in two cases of triplenegative carcinoma pre-NACT, endocrine therapy was performed as residual carcinoma showed hormone receptors expression; the remaining case was a triple-negative carcinoma that changed into luminal B-like HER2-positive and patient became eligible for both trastuzumab and endocrine therapy.

Among the 20 cases of luminal A-like carcinomas on biopsy, seven (35\%) cases changed intrinsic subtype after NACT. All cases became luminal B-like due to loss of the PR expression. A concomitant increase in Ki67 rate was detected in one case. No impact on adjuvant therapy was observed.

Thirty-one (37.8\%) luminal B-like HER2-negative carcinomas changed intrinsic subtype after NACT. Twenty-two cases became luminal A-like, five cases changed into luminallike HER2-positive, and four cases had TN residual carcinoma. In the adjuvant setting, trastuzumab was added in the five luminal HER2-positive cases.

Among 73 cases of luminal B-like Her2-positive carcinomas, 28 (38.4\%) changed intrinsic subtype after NACT. Overall, 19 cases lost HER2 positivity, becoming luminal A-like (11 cases) or luminal B-like (8 cases). In four cases, residual carcinoma was HER2positive non-luminal; the remaining five cases showed only a significant reduction in the Ki67 rate (luminal A-like HER2-positive). Adjuvant therapy was therefore unaffected.

The pre-NACT HER2-positive non-luminal cancers changed the intrinsic subtype in three cases $(9.4 \%)$, becoming luminal B-like HER2-negative in two cases and TN in one case. Both luminal-like cases had endocrine therapy added.

Among $58 \mathrm{TN}$ cases, three (5.2\%) residual carcinomas after NACT revealed a different intrinsic subtype: two cases showed ER expression becoming luminal B-like HER2-negative, and one case was luminal B-like HER2-positive. In all three cases, adjuvant therapy was changed by adding endocrine therapy, and trastuzumab was also added in the latter case.

The correlation between intrinsic subtype change after NACT and clinicopathological features, such as age, $\mathrm{cT}$, stage, histotype, grade, tumor progression or downstaging, was not statistically significant (data not shown). A regression analysis showed no correlation between intrinsic subtype changes and age (R2: 0.000; F: 0.059, sign.: 0.808).

\section{Discussion}

Breast cancer is a heterogeneous disease exhibiting phenotypic and genetic heterogeneity [14].

Both spatial and temporal heterogeneity have been advocated to explain biomarkers change after NACT. Spatial heterogeneity refers to intratumoral diversifications of cancer cells that could impact the representativeness of the biopsied material, while temporal heterogeneity indicates the capability of tumor cells to switch phenotype through a therapyinduced survival-mechanism pressure. The frequency of these phenomena in daily routine in terms of biomarkers changes after NACT, and their real impact on therapy is still largely unknown. Several studies addressed this topic with different results [15-28], and although some authors recommend retesting of biological markers after NACT [15], its actual benefit is debated, with a pathology international working group not currently recommending it [28]. Major limitations of the current literature are that not all laboratories systematically repeated the biological characterization after NACT and very few of them tested Ki67 routinely because of the lack of standardization and reproducibility in its assessment.

Herein, we reported a retrospective consecutive series of 265 invasive breast cancer undergoing NACT, in which a residual tumor was detected. Since, in our institution, we systematically repeat the biological characterization of ER, PR, HER2 and Ki67, we could verify the frequency of each biomarker change, the impact on intrinsic subtype and on subsequent adjuvant therapy. All biomarkers changed with an overall tendency toward a reduced expression. Changes in progesterone receptor and Ki67 were statistically significant $(p=0.001)$, as already described in the literature [18]. 
Ki67 was the biomarker that most frequently changed after NACT, switching from high to low in $40 \%$ of cases and vice versa in a further $3 \%$ of cases. The proliferation rate is commonly reduced by NACT, and the post-treatment Ki67 index has been shown to correlate with the long-term outcome after both neoadjuvant endocrine and chemotherapy $[29,30]$. The update of the Ki67 Working group suggested that, in a neoadjuvant setting, the Ki67 status could be used for an early determination of endocrine therapy efficacy (on biopsy during NACT) to suggest a switch to chemotherapy in the event of an insufficient decrease in this biomarker. Moreover, the same authors concluded that the Ki67 assessment might be of value for a late determination (on surgical specimen post-NACT) of both endocrine and chemotherapy benefit, in order to decide for further therapy or not [31].

Progesterone receptor was the second most frequently switched biomarker (16.6\%). Among a cohort of 446 patients retested after NACT, Ahn et al. reported little changes in the ER and HER2 status, whereas the PR status changed significantly. Furthermore, these authors demonstrated that negative conversion of PR correlated with decreased disease-free survival, thus representing a poor prognostic indicator [23].

HER2 was the most stable biomarker in our series, confirming the same results pre- and post-NACT in $90.2 \%$ of cases. Good concordance of the HER2 status is almost consistent throughout the literature, being HER2 amplification tested with FISH, as in our series, more concordant than HER2 expression measured with immunohistochemistry. A switch to a negative HER 2 receptor up to $43 \%$ of the patients was reported when considering only HER2 positive breast cancers treated with trastuzumab [15,16]. The loss of HER2 positivity in the residual tumor was found to be associated with worse recurrence-free or disease-free survival; this change could therefore potentially indicate the need for further systemic therapy [32-34].

To date, consequences on adjuvant treatment reported in literature were mainly related to the switch of hormone receptors (HR) or HER2 status from negative to positive, allowing adding further therapy.

In 2015, recommendations from an international working group (BIG-NABCG) suggested indeed that a reassessment of hormone receptors and HER2 after neoadjuvant therapy should be considered only in some cases, such as negative results on pretreatment core biopsy and/or no response to therapy. Among a cohort of 83 cases, Xian et al. reported that $25(30 \%)$ patients demonstrated changes in post-NACT biomarker status. Nevertheless, these changes impacted the patient management only in four $(4.8 \%)$ patients that were hormone receptor and/or HER2 negative before NACT [21].

In our seven-year experience, among 265 carcinomas, we almost confirm these data. Intrinsic subtype changed in $72(27.2 \%)$ cases after NACT, and $10(3.8 \%)$ cases switched to a different adjuvant therapy accordingly. In our series, luminal subtypes were the subgroups most likely subject to changes $(31.71 \%$; 66/175). In particular, Luminal B HER2+, which could acquire PR expression lose HER2 positivity or lose all hormone receptors maintaining HER2 positivity. Despite the highest frequency of biomarkers changes, this group is, to date, the less likely to modify its adjuvant therapy.

The TN group was the most stable subtype, but all changes in tumor biomarkers had an impact on the patient treatment: two of them added endocrine therapy due to ER expression, one added both endocrine and trastuzumab due to ER and HER2 positivity.

Of note, regarding HER2-positive and TN breast cancer patients, an update on current ASCO guidelines endorsed a modulation in the adjuvant therapy even in the presence of residual tumor with unchanged intrinsic subtype [35].

The KATHERINE open-label phase III clinical trial showed that among patients with HER 2 positive early breast cancer who had residual disease after NACT, the risk of recurrence or death was 50\% lower with adjuvant trastuzumab emtansine (T-DM1) than with trastuzumab alone [36].

The CREATE-X open-label, phase III trial recently demonstrated that adjuvant capecitabine should be considered for $\mathrm{TN}$ residual cancer since it was shown to increase disease-free 
survival [37]. Moreover, other trials are investigating the possible role of immunotherapy in this setting [38].

\section{Conclusions}

To conclude, we confirm in a large retrospective series that biomarkers' changes after NACT impacted therapy in a small percentage of cases (3.8\%), and all cases were HER2 negative and/or hormone receptors negative. On the other hand, our study demonstrated significant biomarkers' changes occurring in all intrinsic subtypes of breast carcinomas and no statistically significant correlation was found between biomarkers' changes after NACT and clinicopathological features were investigated. Therefore, we can conclude by suggesting that biomarkers retesting after NACT should always be considered to improve both tailored adjuvant therapies and prognostication of patients.

Author Contributions: Conceptualization, M.R., S.C. and E.G.; methodology, G.S., G.B. (Giulia Besutti); collecting data, S.C., E.G., G.F. (Giuseppe Falco), M.F. (Moira Ragazzi), M.F. (Monica Foroni), R.D.C., V.I. and S.M.; formal analysis, G.S.; writing-original draft preparation, S.C. and E.G.; writingreview and editing, M.R., G.S., G.F. (Guglielmo Ferrari) and G.B (Giancarlo Bisagni).; supervision, M.R.; project administration, S.C. All authors have read and agreed to the published version of the manuscript.

Funding: This research received no external funding.

Institutional Review Board Statement: The study was conducted according to the guidelines of the Declaration of Helsinki and approved by the Institutional Review Board of Reggio Emilia (protocol code 305/2019/OSS/IRCCSRE, approved on June 2019).

Informed Consent Statement: Not applicable.

Data Availability Statement: The data presented in this study are available on request from the corresponding author. The data are not publicly available due to ethical committee restrictions.

Conflicts of Interest: The authors declare no conflict of interest.

\section{References}

1. Kaufmann, M.; von Minckwitz, G.; Bear, H.D.; Buzdar, A.; McGale, P.; Bonnefoi, H.; Colleoni, M.; Denkert, C.; Eiermann, W.; Jackesz, R.; et al. Recommendations from an international expert panel on the use of neoadjuvant (primary) systemic treatment of operable breast cancer: New perspectives 2006. Ann. Oncol. Off. J. Eur. Soc. Med. Oncol. 2007, 18, 1927-1934. [CrossRef] [PubMed]

2. Mamounas, E.P.; Fisher, B. Preoperative (neoadjuvant) chemotherapy in patients with breast cancer. Semin. Oncol. 2001, 28, 389-399. [CrossRef]

3. Van der Hage, J.A.; van de Velde, C.J.; Julien, J.P.; Tubiana-Hulin, M.; Vandervelden, C.; Duchateau, L. Preoperative chemotherapy in primary operable breast cancer: Results from the European Organization for Research and Treatment of Cancer trial 10902. J. Clin. Oncol. Off. J. Am. Soc. Clin. Oncol. 2001, 19, 4224-4237. [CrossRef] [PubMed]

4. Kuerer, H.M.; Newman, L.A.; Smith, T.L.; Ames, F.C.; Hunt, K.K.; Dhingra, K.; Theriault, R.L.; Singh, G.; Binkley, S.M.; Sneige, N.; et al. Clinical course of breast cancer patients with complete pathologic primary tumor and axillary lymph node response to doxorubicin-based neoadjuvant chemotherapy. J. Clin. Oncol. Off. J. Am. Soc. Clin. Oncol. 1999, 17, 460-469. [CrossRef]

5. Chollet, P.; Amat, S.; Cure, H.; de Latour, M.; Le Bouedec, G.; Mouret-Reynier, M.A.; Ferriere, J.P.; Achard, J.L.; Dauplat, J.; Penault-Llorca, F. Prognostic significance of a complete pathological response after induction chemotherapy in operable breast cancer. Br. J. Cancer 2002, 86, 1041-1046. [CrossRef]

6. National Comprehensive Cancer Network. Breast Cancer (Version 8.2021). Available online: https://www.nccn.org/ professionals/physician_gls/pdf/breast.pdf (accessed on 13 September 2021).

7. Cardoso, F.; Paluch-Shimon, S.; Senkus, E.; Curigliano, G.; Aapro, M.S.; André, F.; Barrios, C.H.; Bergh, J.; Bhattacharyya, G.S.; Biganzoli, L.; et al. 5th ESO-ESMO international consensus guidelines for advanced breast cancer (ABC 5). Ann. Oncol. Off. J. Eur. Soc. Med. Oncol. 2020, 31, 1623-1649. [CrossRef]

8. Goldhirsch, A.; Winer, E.P.; Coates, A.S.; Gelber, R.D.; Piccart-Gebhart, M.; Thürlimann, B.; Senn, H.J. Personalizing the treatment of women with early breast cancer: Highlights of the St Gallen international expert consensus on the primary therapy of early breast cancer 2013. Ann. Oncol. Off. J. Eur. Soc. Med. Oncol. 2013, 24, 2206-2223. [CrossRef]

9. Cortazar, P.; Zhang, L.; Untch, M.; Mehta, K.; Costantino, J.P.; Wolmark, N.; Bonnefoi, H.; Cameron, D.; Gianni, L.; Valagussa, P.; et al. Pathological complete response and long-term clinical benefit in breast cancer: The CTNeoBC pooled analysis. Lancet 2014, 384, 164-172. [CrossRef] 
10. Hammond, M.E.; Hayes, D.F.; Wolff, A.C.; Mangu, P.B.; Temin, S. American society of clinical oncology/college of american pathologists guideline recommendations for immunohistochemical testing of estrogen and progesterone receptors in breast cancer. J. Oncol. Pract. 2010, 6, 195-197. [CrossRef]

11. Ragazzi, M.; Bisagni, A.; Gasparini, E.; Kuhn, E.; Bassano, C.; Tamagnini, I.; Foroni, M.; Bortesi, M.; Falco, G.; Ferrari, G.; et al. Impact of 2013 ASCO/CAP guidelines on HER2 determination of invasive breast cancer: A single institution experience using frontline dual-color FISH. Breast 2017, 34, 65-72. [CrossRef]

12. Wolff, A.C.; Hammond, M.E.; Hicks, D.G.; Dowsett, M.; McShane, L.M.; Allison, K.H.; Allred, D.C.; Bartlett, J.M.; Bilous, M.; Fitzgibbons, P.; et al. Recommendations for human epidermal growth factor receptor 2 testing in breast cancer: American Society of Clinical Oncology/College of American Pathologists clinical practice guideline update. J. Clin. Oncol. Off. J. Am. Soc. Clin. Oncol. 2013, 31, 3997-4013. [CrossRef]

13. Amin, M.B.; Edge, S.B.; Greene, F.L.; Byrd, D.R.; Brookland, R.K.; Washington, M.K.; Gershenwald, J.E.; Compton, C.C.; Hess, K.R.; Sullivan, D.C.; et al. (Eds.) AJCC Cancer Staging Manual; Springer International Publishing: Cham, Switzerland, 2017; ISBN 978-3-319-40617-6.

14. Turashvili, G.; Brogi, E. Tumor heterogeneity in breast cancer. Front. Med. 2017, 4, 227. [CrossRef]

15. Van de Ven, S.; Smit, V.T.; Dekker, T.J.; Nortier, J.W.; Kroep, J.R. Discordances in ER, PR and HER2 receptors after neoadjuvant chemotherapy in breast cancer. Cancer Treat. Rev. 2011, 37, 422-430. [CrossRef]

16. Li, P.; Liu, T.; Wang, Y.; Shao, S.; Zhang, W.; Lv, Y.; Yi, J.; Wang, Z. Influence of neoadjuvant chemotherapy on HER2/neu status in invasive breast cancer. Clin. Breast Cancer 2013, 13, 53-60. [CrossRef]

17. Yang, Y.F.; Liao, Y.Y.; Li, L.Q.; Xie, S.R.; Xie, Y.F.; Peng, N.F. Changes in ER, PR and HER2 receptors status after neoadjuvant chemotherapy in breast cancer. Pathol. Res. Pract. 2013, 209, 797-802. [CrossRef]

18. Ge, W.K.; Yang, B.; Zuo, W.S.; Zheng, G.; Dai, Y.Q.; Han, C.; Yang, L.; Zheng, M.Z. Evaluation of hormone receptor, human epidermal growth factor receptor-2 and Ki-67 with core needle biopsy and neoadjuvant chemotherapy effects in breast cancer patients. Thorac. Cancer 2015, 6, 64-69. [CrossRef]

19. Qin, Q.; Gao, F.; Jiang, W.; Tan, Q.; Mo, Q.; Wei, C. Effect of neoadjuvant chemotherapy on expressions of estrogen receptor, progesterone receptor, human epidermal growth factor receptor 2, and Ki-67 in breast cancer. Chin. Med. J. 2014, 127, 3272-3277.

20. Lim, S.K.; Lee, M.H.; Park, I.H.; You, J.Y.; Nam, B.H.; Kim, B.N.; Ro, J.; Lee, K.S.; Jung, S.Y.; Kwon, Y.M.; et al. Impact of molecular Subtype conversion of breast cancers after neoadjuvant chemotherapy on clinical outcome. Cancer Res. Treat. 2016, 48, 133-141. [CrossRef]

21. Xian, Z.; Quinones, A.K.; Tozbikian, G.; Zynger, D.L. Breast cancer biomarkers before and after neoadjuvant chemotherapy: Does repeat testing impact therapeutic management? Hum. Pathol. 2017, 62, 215-221. [CrossRef]

22. De La Cruz, L.M.; Harhay, M.O.; Zhang, P.; Ugras, S. Impact of neoadjuvant chemotherapy on breast cancer Subtype: Does subtype change and, if so, how? IHC profile and neoadjuvant chemotherapy. Ann. Surg. Oncol. 2018, 25, 3535-3540. [CrossRef]

23. Ahn, S.; Kim, H.J.; Kim, M.; Chung, Y.R.; Kang, E.; Kim, E.K.; Kim, S.H.; Kim, Y.J.; Kim, J.H.; Kim, I.A.; et al. Negative conversion of progesterone receptor status after primary systemic therapy is associated with poor clinical outcome in patients with breast cancer. Cancer Res. Treat. 2018, 50, 1418-1432. [CrossRef] [PubMed]

24. Rey-Vargas, L.; Mejía-Henao, J.C.; Sanabria-Salas, M.C.; Serrano-Gomez, S.J. Effect of neoadjuvant therapy on breast cancer biomarker profile. BMC Cancer 2020, 20, 675. [CrossRef] [PubMed]

25. Rossi, L.; Verrico, M.; Tomao, S.; Ricci, F.; Fontana, A.; Spinelli, G.P.; Colonna, M.; Vici, P.; Tomao, F. Expression of ER, PgR, HER-2, and $\mathrm{Ki}-67$ in core biopsies and in definitive histological specimens in patients with locally advanced breast cancer treated with neoadjuvant chemotherapy. Cancer Chemother. Pharmacol. 2020, 85, 105-111. [CrossRef] [PubMed]

26. Mohan, S.C.; Walcott-Sapp, S.; Lee, M.K.; Srour, M.K.; Kim, S.; Amersi, F.F.; Giuliano, A.E.; Chung, A.P. Alterations in breast cancer biomarkers following neoadjuvant therapy. Ann. Surg. Oncol. 2021, 28, 5907-5917. [CrossRef]

27. Jeong, Y.H.; Hong, S.A.; Ahn, H.S.; Ahn, S.K.; Kim, M.K. Clinicopathologic factors affecting discrepancies in HER2 overexpression between core needle biopsy and surgical biopsy in breast cancer patients according to neoadjuvant treatment or not. J. Cancer 2021, 12, 4722-4728. [CrossRef]

28. Provenzano, E.; Bossuyt, V.; Viale, G.; Cameron, D.; Badve, S.; Denkert, C.; MacGrogan, G.; Penault-Llorca, F.; Boughey, J.; Curigliano, G.; et al. Standardization of pathologic evaluation and reporting of postneoadjuvant specimens in clinical trials of breast cancer: Recommendations from an international working group. Mod. Pathol. Off. J. United States Can. Acad. Pathol. Inc. 2015, 28, 1185-1201. [CrossRef]

29. Ellis, M.J.; Tao, Y.; Luo, J.; A’Hern, R.; Evans, D.B.; Bhatnagar, A.S.; Chaudri Ross, H.A.; von Kameke, A.; Miller, W.R.; Smith, I.; et al. Outcome prediction for estrogen receptor-positive breast cancer based on postneoadjuvant endocrine therapy tumor characteristics. J. Natl. Cancer Inst. 2008, 100, 1380-1388. [CrossRef]

30. Jones, R.L.; Salter, J.; A'Hern, R.; Nerurkar, A.; Parton, M.; Reis-Filho, J.S.; Smith, I.E.; Dowsett, M. The prognostic significance of Ki67 before and after neoadjuvant chemotherapy in breast cancer. Breast Cancer Res. Treat. 2009, 116, 53-68. [CrossRef]

31. Nielsen, T.O.; Leung, S.C.Y.; Rimm, D.L.; Dodson, A.; Acs, B.; Badve, S.; Denkert, C.; Ellis, M.J.; Fineberg, S.; Flowers, M.; et al. Assessment of Ki67 in breast cancer: Updated recommendations from the international Ki67 in breast cancer working group. J. Natl. Cancer Inst. 2021, 113, 808-819. [CrossRef] 
32. Mittendorf, E.A.; Wu, Y.; Scaltriti, M.; Meric-Bernstam, F.; Hunt, K.K.; Dawood, S.; Esteva, F.J.; Buzdar, A.U.; Chen, H.; Eksambi, S.; et al. Loss of HER2 amplification following trastuzumab-based neoadjuvant systemic therapy and survival outcomes. Clin. Cancer Res. Off. J. Am. Assoc. Cancer Res. 2009, 15, 7381-7388. [CrossRef]

33. Wang, T.; Xu, Y.; Sheng, S.; Yuan, H.; Ouyang, T.; Li, J.; Wang, T.; Fan, Z.; Fan, T.; Lin, B.; et al. HER2 somatic mutations are associated with poor survival in HER2-negative breast cancers. Cancer Sci. 2017, 108, 671-677. [CrossRef]

34. Guarneri, V.; Dieci, M.V.; Barbieri, E.; Piacentini, F.; Omarini, C.; Ficarra, G.; Bettelli, S.; Conte, P.F. Loss of HER2 positivity and prognosis after neoadjuvant therapy in HER2-positive breast cancer patients. Ann. Oncol. Off. J. Eur. Soc. Med. Oncol. 2013, 24, 2990-2994. [CrossRef]

35. Korde, L.A.; Somerfield, M.R.; Carey, L.A.; Crews, J.R.; Denduluri, N.; Hwang, E.S.; Khan, S.A.; Loibl, S.; Morris, E.A.; Perez, A.; et al. Neoadjuvant chemotherapy, endocrine therapy, and targeted therapy for breast cancer: ASCO guideline. J. Clin. Oncol. Off. J. Am. Soc. Clin. Oncol. 2021, 39, 1485-1505. [CrossRef]

36. Masuda, N.; Lee, S.J.; Ohtani, S.; Im, Y.H.; Lee, E.S.; Yokota, I.; Kuroi, K.; Im, S.A.; Park, B.W.; Kim, S.B.; et al. Adjuvant capecitabine for breast cancer after preoperative chemotherapy. N. Engl. J. Med. 2017, 376, 2147-2159. [CrossRef]

37. Von Minckwitz, G.; Huang, C.S.; Mano, M.S.; Loibl, S.; Mamounas, E.P.; Untch, M.; Wolmark, N.; Rastogi, P.; Schneeweiss, A.; Redondo, A.; et al. Trastuzumab emtansine for residual invasive HER2-positive breast cancer. N. Engl. J. Med. 2019, 380, 617-628. [CrossRef]

38. Conte, P.F.; Dieci, M.V.; Bisagni, G.; Laurentiis, M.D.; Tondini, C.A.; Schmid, P.; Salvo, G.L.D.; Moratello, G.; Guarneri, V. Phase III randomized study of adjuvant treatment with the ANTI-PD-L1 antibody avelumab for high-risk triple negative breast cancer patients: The A-BRAVE trial. J. Clin. Oncol. 2020, 38, TPS598. [CrossRef] 